\title{
Synovial sarcoma
}

INSERM

\section{Source}

INSERM. (1999). Orphanet: an online rare disease and orphan drug data base. Synovial sarcoma. ORPHA:3273

Synovial sarcoma is an aggressive soft tissue sarcoma (see this term), occurring most commonly in adolescents and young adults (15 to 40 years), usually localized near the large joints of the extremities but also in the head and neck, mediastinum and viscera (lung, kidney etc), clinically presenting as a deep seated swelling or a painful mass often with an initial indolent course and is characterized by its local invasiveness and a propensity to metastasize. The origin of synovial sarcoma is likely from multipotent mesenchymal cells and not synovium (contrary to its name). 